Table 1. Clinical characteristics

\begin{tabular}{|c|c|c|c|c|c|}
\hline $\begin{array}{l}\text { Systemic / } \\
\text { Extracranial Findings }\end{array}$ & $78(\% 87,6)$ & Cranial Findings & $69(\% 77,5)$ & $\begin{array}{l}\text { Opthalmologic } \\
\text { Findings }\end{array}$ & $\begin{array}{c}20 \\
(\% 22,5)\end{array}$ \\
\hline Fatigue & $\begin{array}{c}72 \\
(\% 80,9)\end{array}$ & Headache & $60(\% 67,4)$ & $A V L$ & $\begin{array}{c}16 \\
(\% 18,8)\end{array}$ \\
\hline Weight loss & $\begin{array}{c}47 \\
(\% 52,8)\end{array}$ & Jaw claudication & $33(\% 37,1)$ & Unilateral & $\begin{array}{c}12 \\
(\% 13,5)\end{array}$ \\
\hline Arthralgia & $\begin{array}{c}43 \\
(\% 48,3)\end{array}$ & Scalp / TA Tenderness & s $\begin{array}{c}27 \\
(\% 30,3)\end{array}$ & Bilateral & $4(\% 4,5)$ \\
\hline Fever & $\begin{array}{c}35 \\
(\% 39,3)\end{array}$ & $\begin{array}{c}\text { Decreased pulsation } \\
\text { of TA }\end{array}$ & $11(\% 12,4)$ & Diplopia & $4(\% 4,5)$ \\
\hline Arthritis & $13(\% 14,6)$ & CVE & $6(\% 6,7)$ & & \\
\hline Vascular murmur & $3(\% 3,4)$ & Swollen TA & $6(\% 6,7)$ & & \\
\hline Pericardial effusion & $2(\% 2,2)$ & Vertigo & $5(\% 5,6)$ & & \\
\hline Extremity Claudication & $1(\% 1,1)$ & & & & \\
\hline
\end{tabular}

TABLE 2 Treatment data of GCA cohort

Initial glucocorticoid $(\mathrm{GC})$ dosage $(\mathrm{mg})$

Pulse GC treatment

12nd month cumulative GC dosage $(\mathrm{g})$

MTX usage

bDMARD usage

Acetyl salicylic acid usage

Disclosure of Interests: None declared

DOI: 10.1136/annrheumdis-2020-eular.1163

\section{AB0487 TAKAYASU'S ARTERITIS: RECOGNIZING AN OLD ENEMY}

F. Torres ${ }^{1}$, D. Jaramillo Arroyave ${ }^{1,2,3,4}$, C. Muñoz ${ }^{1,2,3,4}$, L. Hernandez $z^{1,2,5}$ G. Vásquez ${ }^{1}$, M. Restrepo Escobar ${ }^{1}$, L. A. González ${ }^{1}$, A. Vanegas ${ }^{1,2,3}$. ${ }^{1}$ Universidad de Antioquia - Grupo de Reumatología, Medellin, Colombia; ${ }^{2}$ Universidad de Antioquia - Grupo de Estudio de las Vasculitis Sistémicas, Medellin, Colombia; ${ }^{3}$ Hospital Universitario San Vicente Fundacion, Medellin, Colombia: ${ }^{4}$ IPS Universitaria, Servicios de Salud Universidad de Antioquia, Medellin, Colombia; ${ }^{5}$ Universidad de Antioquia - Departamento de Pediatria, Medellin, Colombia

Background: Takayasu's arteritis (AT) is a systemic vasculitis that affects large vessels, mainly the aorta, its branches and the pulmonary arteries. There are few data on their behavior in our region.

Objectives: to describe the clinical and angiographic characteristics and outcomes of a group of patients with AT.

Methods: a cross-sectional, retrospective study based on a secondary source taken from two high complexity hospitals in Medellin - Colombia between August 2011 and December 2018.

Results: medical records of 41 patients were evaluated, $87.5 \%$ met the 1990 ACR criteria of AT. The majority were women $(95.1 \%)$, with a median age at the time of diagnosis of 22 years (IR 52), 11 patients (26.8\%) were over 40 years old at debut. The median delay in diagnosis was 12 months (IR: 167). Systemic symptoms included general malaise (29.3\%), weight loss $(29.3 \%)$ and fever $(19.5 \%)$; the main vascular manifestations were hypertension and blood pressure difference $(61 \%)$, headache (39\%), upper limb claudication (31.7\%), dyspnea (29.3\%), angina $(26.8 \%)$ and carotidinia (22\%). Most frequent findings on physical examination were pulse absence or decrease (78\%) and subclavian murmur (53.7\%). ESR and CRP were found high in $85.3 \%$ and $22 \%$, respectively. Angiographic studies revealed stenosis or occlusion in multiple arterial territories, being the stenosis of the left subclavian artery the most frequent lesion $(68.3 \%)$, followed by the involvement of the abdominal aorta $(58.5 \%)$ and thoracic $(51 \%)$. The distribution according to Hata-Numano classification was: type V (58.5\%), type I (17.1\%) and type Ila (7.3\%), indicating complex vascular lesions and associated serious complications. Abnormalities of the renal arteries, pulmonary arteries involvement, and aortic insufficiency were present in $39 \%, 14.6 \%$, and $7.3 \%$ respectively. Seventy-five percent of patients had active disease, glucocorticoids were the main treatment in $90.2 \%$ of the cases, used isolated $(2.4 \%)$ or in combination with other immunosuppressants $(87.8 \%)$, including methotrexate $(75.6 \%)$, azathioprine $(26.8 \%)$ and cyclophosphamide (14.6\%); vascular interventions were performed in 11 patients $(26.8 \%)$. Most relevant vascular complications were renovascular hypertension (26.8\%), stroke (19.5\%), chronic kidney disease $(19.5 \%)$ and chronic heart failure (17.1\%). From the clinical point of view, our findings were similar to those shown in series from Brazil, Japan, and Turkey. Contrary to what was reported in other series, carotidinia was a finding that occurred in almost a quarter of our patients $(23 \%)$ and maybe one of the initial symptoms of the disease. The findings of the vascular physical examination are similar to those reported by the IRAVAS group, where the asymmetry of the pulses was most frequent, followed by the presence of murmurs and the difference in blood pressure, claudication being less frequent in the upper and lower limbs.

Conclusion: patients in this series are characterized by having an extensive disease partly due to a late diagnosis, with a high percentage of complications associated with vascular stenotic compromise, which generates morbidity and impact on the quality of life.

References:

[1] Sato El, et al. Takayasu arteritis. Treatment and prognosis in a university center in Brazil, Int J Cardiol. 2000; 75 Suppl 1: S163-6.

[2] Arnaud L, et al. Takayasu arteritis in France: a single-center retrospective study of 82 cases comparing white, North African, and black patients. Medicine (Baltimore). 2010; 89(1): 1-17.

Disclosure of Interests: : None declared

DOI: 10.1136/annrheumdis-2020-eular.6605

\section{AB0488 $\quad$ CAN A GCA RISK STRATIFICATION SCORE BE HELPFUL IN CLINICAL PRACTICE?}

M. Jasim ${ }^{1}$, P. Magan ${ }^{1}$, R. Awadalla ${ }^{1}$, R. Brindley ${ }^{1}$, D. Richards ${ }^{1}$, A. Hall ${ }^{1}$ J. Barraclough', T. Adizie ${ }^{1} .{ }^{1}$ Royal Wolverhampton NHS Trust, Wolverhampton, United Kingdom

Background: Giant cell arteritis (GCA) is the most common type of large vessel vasculitis. Typically it presents in patients over the age of 50 with a combination of temporal headaches, scalp tenderness, jaw claudication, raised inflammatory markers and visual disturbance. The diagnosis of GCA is often challenging and there is a difficult balance of over and under investigation. There have been several proposed scoring systems to help clinicians risk stratify patients who may present with suspected GCA. One such scoring system, published in 2017 showed clinical utility in a large international multi-centre study. Following analysis

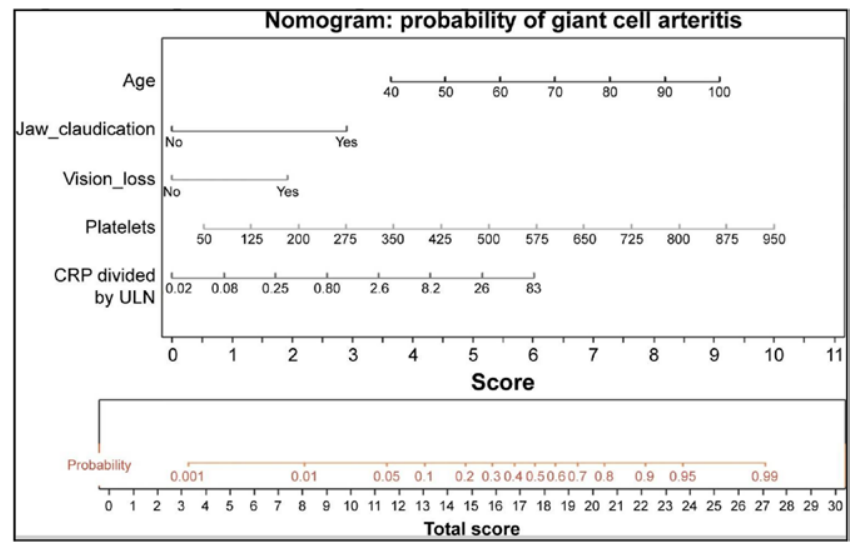

Figure 1. Ing et al's Nomogram of parsimonious model.

by logistic regression on data from 530 biopsies, Ing et al. developed a parsimonious prediction model comprising 5 candidate criteria: age, jaw claudication ischemia-related loss of visual acuity, platelet count and logCRP (Figure 1). ${ }^{11]}$ Objectives: Increasingly, ultrasound doppler imaging is recognised and accepted as satisfactory means of confirming the diagnosis of GCA, with the presence of the halo sign characteristic for GCA. The aim of our study was to determine whether this GCA prediction model accurately predicts positive temporal artery biopsies in a large, real world UK cohort. In addition, we assessed whether this model accurately predicts positive temporal artery ultrasounds.

Methods: A retrospective cohort study was performed using electronic medical records of patients referred for temporal artery biopsy (TAB) and temporal artery ultrasound (USTA) for suspected GCA. All TAB performed at the Royal Wolverhampton NHS Trust between June 2014 - June 2018 and all USTA performed between January 2015 - January 2019 were analysed. Patients who undergo USTA for suspected GCA at our centre routinely have bilateral temporal and axillary arteries scanned. Patients were excluded if they already had a previous diagnosis of GCA (and the clinical question was suspected flare), or if there was insufficient information available.

Results: The total number of patients who underwent a confirmatory diagnostic test (either TAB or USTA) for suspected GCA was 187. Thirteen of these patients met the exclusion criteria, the remaining 174 patients were included for analysis. 126/174 patients underwent a TAB, 63/174 had an USTA. 15/174 had both these were included in the USS cohort because for all these patients the ultrasound was the first diagnostic test performed (Table 1). Our results appear to closely mirror the original multi-centre results with regards to prediction of biopsy positive GCA, with the centiles closely following those in the inception cohort. $0 \%$ of the 'low' risk probability biopsy cohort were misclassified - none had a positive biopsy. However, $8 \%$ of the 'low' risk probability ultrasound cohort were misclassified -2 had a positive ultrasound. 